\title{
Diferenciação dos solos em duas topossequências sobre rochas basálticas no norte-central paranaense
}

\section{Soil differentiation in two toposequences developed from basaltic rocks in North-Central region of the Paraná State, Brazil}

\author{
Marcos Aparecido Gonçalves'; Tiago Santos Telles²; João Henrique Caviglione ${ }^{3}$; \\ Alexandre Urbano ${ }^{4}$; João Tavares Filho ${ }^{5 *}$
}

\begin{abstract}
Em regiões com ocorrência de derrames basálticos, variações na granulometria e na composição da rocha, devido à segregação magmática e a sobreposição dos derrames, produzem relevos característicos, com influência sobre os atributos físicos e químicos do solo. Nesse contexto, o trabalho foi conduzido com o objetivo de caracterizar duas topossequências tendo como embasamento rochoso o basalto, buscando identificar a influência de suas variações na formação do solo, nos atributos morfológicos e na distribuição destes ao longo da vertente. O estudo foi realizado em uma área do Terceiro Planalto do Paraná, na Formação Serra Geral. Foram estabelecidas duas topossequências com transectos equidistantes $2.000 \mathrm{~m}$, ambas com mesmo sentido (sudoeste-nordeste), porém distintos quanto ao relevo e material de origem. Denominou-se vertente relevo ondulado (VRO) e vertente relevo suave ondulado (VSO), nas quais foram realizadas descrição morfológica dos perfis com identificação das classes de solo, análises químicas e a mineralogia da fração argila. Os resultados permitiram concluir que a dinâmica interna e o processo de segregação magmática foram os principais responsáveis pelas formas de relevo e pelo tipo de rocha formada, com significativa variação do solo formado quando da ocorrência de variações em uma mesma rocha. As formas do relevo e a diferenciação do basalto tiveram importância significativa na evolução e distribuição de solos na vertente com horizontes B distintos, nominados no trabalho de B nítico e B latossólico.
\end{abstract}

Palavras-chave: Relevo, material de origem, Nitossolo, dinâmica interna

\section{Resumo}

In regions where there were basaltic rocks formation due to magmatic flows, variation in particle sizes and rock composition determine characteristic reliefs influencing chemical and physical attributes. The aim of the article was to characterize two different toposequences over basaltic rock basis, in order to identify the influence of their variation in soil formation, morphological properties and their distribution along the slope. The study was carried out in the Third Plateau of Parana State, Brazil, at Serra Geral geological formation, There were chosen two toposequences in equidistant $2000 \mathrm{~m}$ parallel transects in southwest-northeast direction with different relief and rock composition and features. It was named

\footnotetext{
${ }^{1}$ Eng $^{\mathrm{o}}$ Agr ${ }^{\mathrm{o}}$, Ministério do Desenvolvimento Agrário, Brasília, DF. E-mail: marcos.goncalves@mda.gov.br.

2 Pesquisador B do Instituto Agronômico do Paraná, IAPAR, Londrina, PR. E-mail: telles@iapar.br

${ }^{3}$ Pesquisador do IAPAR, Londrina, PR. E-mail: caviglione@iapar.br

${ }^{4}$ Prof. do Dept ${ }^{\mathrm{O}}$ de Física, Universidade Estadual de Londrina, UEL, Londrina, PR. E-mail: aurbano@uel.br

${ }^{5}$ Prof. Associado C, Dept ${ }^{\circ}$ de Agronomia, UEL, Londrina, PR. E-mail: tavares@uel.br

* Autor para correspondência
} 
undulated relief slope (VRO) and gently undulated relief slope (VSO) in which there were carried out profile morphological description with soil classes identifying, chemical analysis and clay mineralogical analysis. The results permitted to conclude that the internal dynamic and the magmatic segregation process were responsible for relief shapes and rock types formed with significant variation in soil types according variation in composition in the same rock, Both relief shapes and basalt differentiation had strong influence in soil evolution level and soil type distribution along the slopes with distinct B horizons, Nitic B and Latosolic B.

Key words: Relief, parental rock material, Nitosol, internal dynamics

\section{Introdução}

Em regiões com ocorrência de derrames basálticos, variações na granulometria e na composição da rocha, devido à segregação magmática e a sobreposição dos derrames, produzem relevos característicos (BELLIENE et al., 1986; THOMAZ, 2008), com influência sobre os atributos físicos e químicos do solo, Além disso, o relevo, que regula o escoamento superficial, a drenagem e a movimentação vertical e horizontal da água, tem influência no tempo de exposição dos materiais à ação do intemperismo (MILNE, 1935; RUHE, 1956; CAMPOS et al., 2010) e nas alterações dos atributos do solo, favorecendo a identificação de superfícies geomorfológicas, genética e evolutivamente interdependentes (BOCKHEIM et al., 2005).

A disposição do relevo além de influenciar a dinâmica da água (PACHEPSKY; TIMLIN; RAWLS, 2001; VIDAL-TORRADO; LEPSCH; CASTRO, 2005), favorece o mecanismo de translocação (SILVA et al., 2007; COOPER; VIDAL-TORRADO; GRIMALDI, 2010), os quais podem influenciar os teores das frações orgânicas, a espessura do solo (SOUZA JÚNIOR; DEMATTÊ, 2008) e a saturação por bases (CAMPOS et al., 2007; SANTOS et al., 2010).

O substrato rochoso tem grande influência na formação do solo, visto que rochas diferentes levam a formação de solos distintos, Ademais, sabe-se que a distribuição regional predominante dos solos se dá de acordo com as características geológicas, No entanto, nem sempre é clara a influência deste fator em tal processo e nas variações dos atributos dos solos, principalmente quando o material de origem é heterogêneo.

Nesse contexto, o trabalho foi conduzido com o objetivo de caracterizar duas topossequências tendo como embasamento rochoso o basalto, entre os municípios de Bela Vista do Paraíso e Alvorada do Sul, no estado do Paraná, buscando identificar a influência de suas variações na formação do solo, nos atributos morfológicos e na distribuição destes ao longo da vertente.

\section{Material e Métodos}

O estudo foi realizado em uma área de 1.055 ha, localizada no Terceiro Planalto do Paraná, na Formação Serra Geral, entre os municípios de Bela Vista do Paraíso e Alvorada do Sul (22 ${ }^{\circ} 55^{\prime} \mathrm{S}$; $51^{\circ} 13^{\prime} \mathrm{O}$ ) (Figura 1), tendo como embasamento rochoso lavas basálticas, e material de origem produto da alteração das rochas oriundas deste derrame e de materiais coluviais. Nas partes mais altas, são observados vestígios de material sedimentar de rochas areníticas suprajacentes (Arenito Caiuá), sem a presença da rocha. O clima, segundo classificação de Köppen, é Cfa, com tendência de concentração das chuvas nos meses de verão, porém, sem estação seca definida. A precipitação média anual é de $1.588 \mathrm{~mm}$.

Foram estabelecidas duas topossequências com transectos equidistantes $2.000 \mathrm{~m}$, Ambos com mesmo sentido (sudoeste-nordeste), porém distintos quanto ao relevo e material de origem. Denominouse vertente relevo ondulado (VRO) e vertente relevo suave ondulado (VSO) (Figura 1). 
A VRO com $2.500 \mathrm{~m}$ de extensão, altitude média de $505 \mathrm{~m}$, relevo ondulado (declividade média entre $10-12 \%$ ) no segmento inferior (primeiros 700 $\mathrm{m})$ e suave ondulado (declividade média entre 4 6\%) no segmento superior (1.100 m posteriores). Próximo ao curso d'água é ocupada por mata em estado intermediário de regeneração e nas demais áreas, pastagem, frutíferas e culturas anuais. A VSO possui $2.000 \mathrm{~m}$ de extensão, altitude média de $497 \mathrm{~m}$, sentido sudoeste-nordeste, relevo suave ondulado e declividade média de $6 \%$ em toda sua extensão, A área é utilizada principalmente com culturas anuais, com pequeno segmento ocupado por pastagem.

Figura 1. Localização da área de estudo, com detalhe dos transectos, da topografia local e da posição dos perfis.

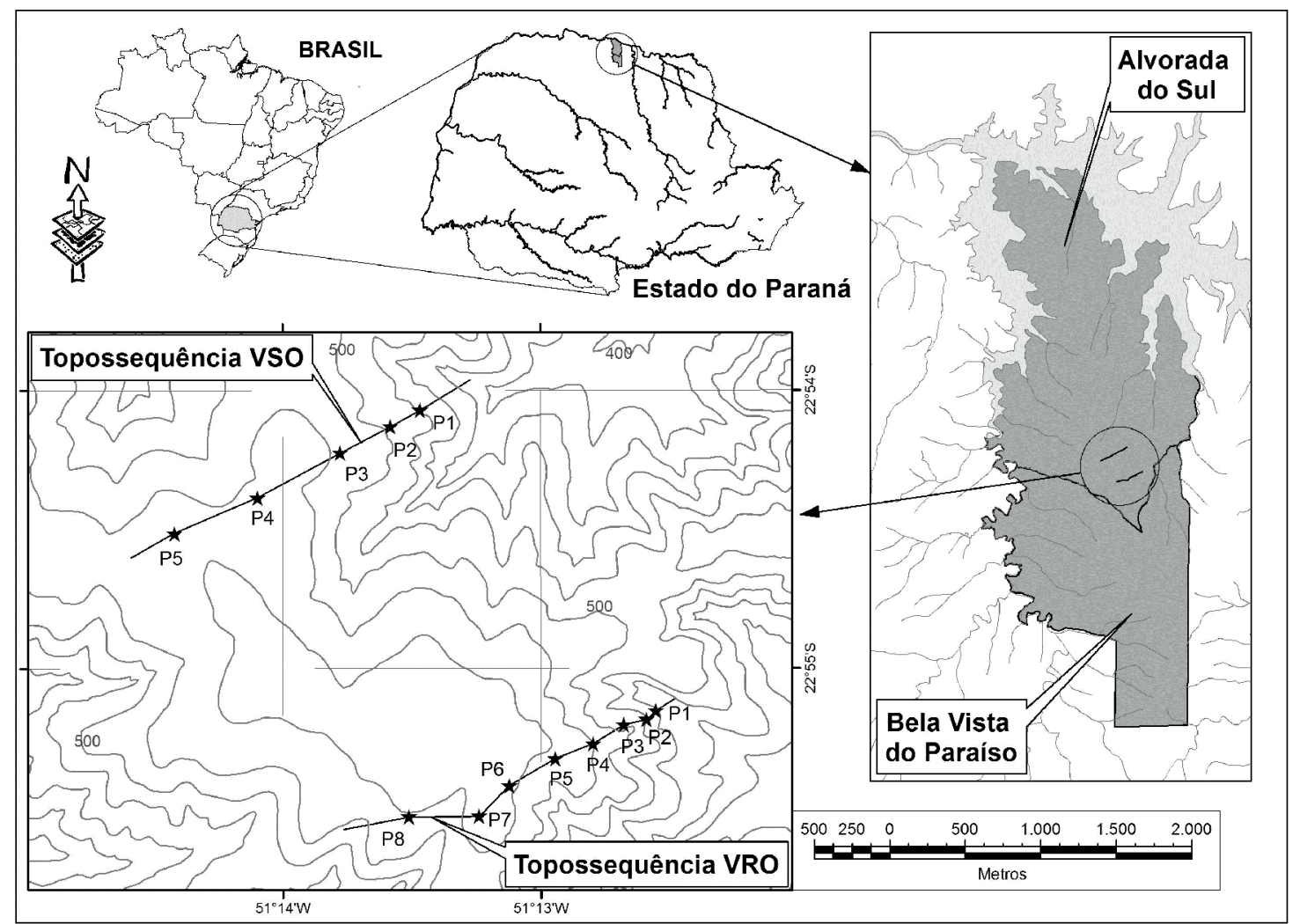

Fonte: Elaboração dos autores.

Tradagens equidistantes no máximo em 100 $\mathrm{m}$ foram feitas ao longo dos transectos para a delimitação das principais variações quanto às classes de solos, sendo observadas também as características do relevo, Foram identificadas as unidades litológicas subjacentes em cada segmento. Em seguida, foi aberta uma trincheira em cada segmento do relevo, ou local representativo da unidade de solo dominante, para delimitação e denominação de distintas unidades geomorfológicas.
Tais perfis estão representados nas Figuras 2 e 3, bem como a disposição destes na topossequência, e a distribuição dos horizontes, de modo a descrever a paisagem pedológica nos dois transectos.

As trincheiras foram abertas com dimensão de $2,0 \times 1,0 \times 1,0 \mathrm{~m}$ (comprimento, largura e profundidade, respectivamente), onde foi realizada a delimitação dos horizontes e sub-horizontes com a descrição morfológica do perfil (SANTOS et al., 2005). Após a descrição morfológica dos perfis, 
amostras foram coletadas em todos os horizontes para as análises químicas, como determinação dos teores de $\mathrm{Ca}^{2+}, \mathrm{Mg}^{2+}, \mathrm{P}, \mathrm{K}^{+}, \mathrm{C}$ e $\mathrm{pH}$ (EMBRAPA,
1997). Além disso, foram calculados a soma de bases (SB), capacidade de troca de cátions (CTC) e saturação por bases (V\%).

Figura 2. Esquema da topossequência VRO com a representação e a disposição dos perfis.
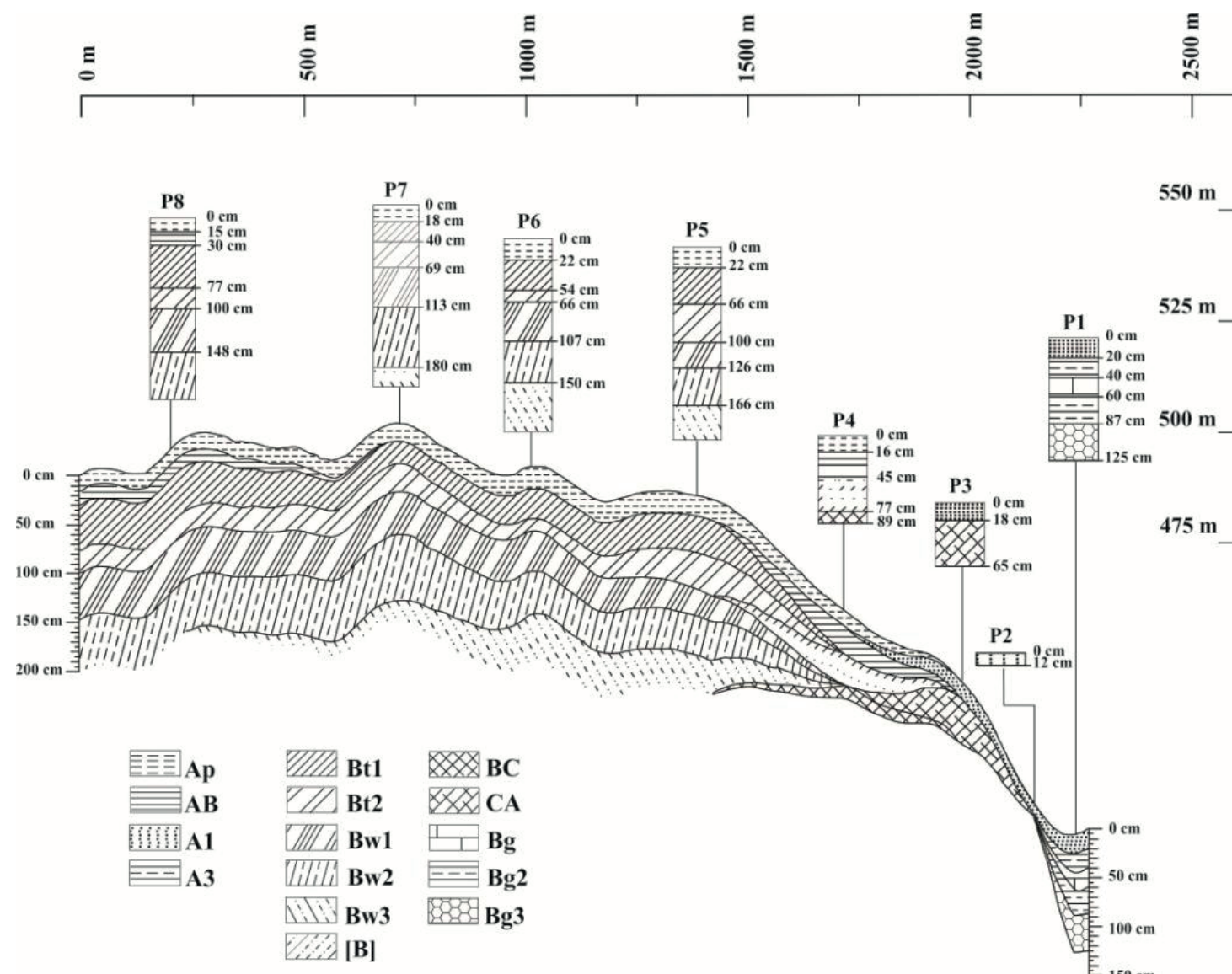

Fonte: Elaboração dos autores. 
Figura 3. Esquema da topossequência VSO com a representação e a disposição dos perfis.
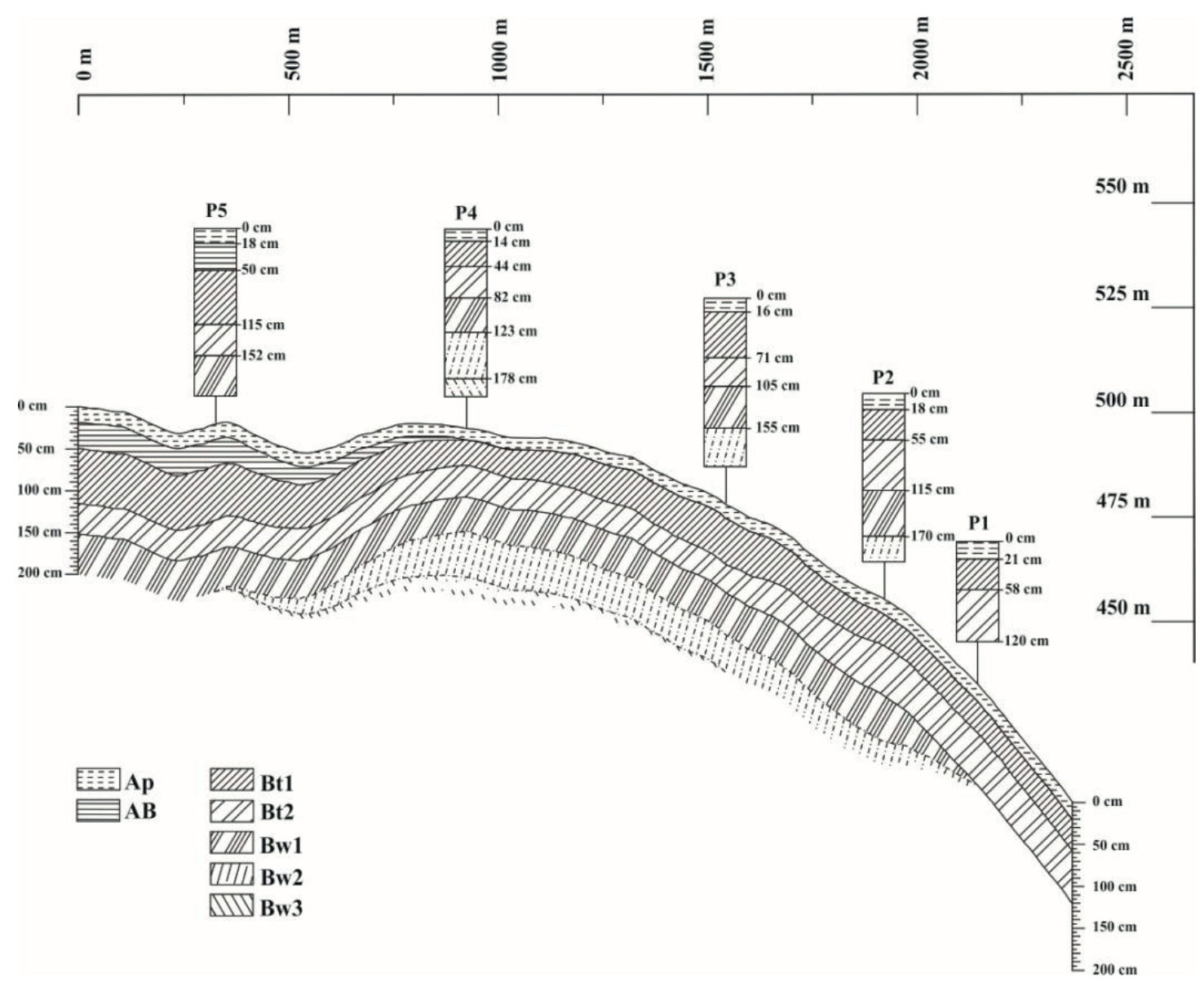

Fonte: Elaboração dos autores.

Também foi realizada a análise de Difração de Raios X da fração argila ( $<2$ um) dos horizontes representativos de cada vertente, após esta fração ser separa por sedimentação (EMBRAPA, 1997), As análises foram realizadas sob geometria BraggBrentano, passo angular de $0,05^{\circ}$ a cada 5 s $(0,01$ \%s), radiação de cobre $K_{\alpha}(\lambda=1,54060 \AA$ ), tensão de $40 \mathrm{kV}$, corrente de $50 \mathrm{~mA}$.

Os perfis foram classificados até o quarto nível categórico, segundo o Sistema Brasileiro de Classificação de Solos (SiBCS) (SANTOS et al., 2006).

\section{Resultados e Discussão}

Relevo e material de origem
A VRO apresenta relevo variável, sendo a parte inferior do relevo de classe de relevo ondulado, e os solos na sequencia são rasos, mesmo nas áreas de baixa declividade (2-4\%). No primeiro segmento da vertente o relevo muda constantemente de regiões planas (P1 e P3) para regiões declivosas (P2 e P4) (Tabela 1), e ocorrem os Neossolos, com predominância dos Regolíticos; e Gleissolo, na margem do curso d'água em relevo plano (Figura 2). Observa-se diferenciação na evolução do solo devida ao relevo, e ocorrência de solos jovens em locais planos; provavelmente, o material de origem está condicionando a intensidade do intemperismo e a pedogênese.

Quanto ao material de origem, no segmento inferior da VRO, ocorre principalmente basalto amigdaloidal e vesicular bastante resistentes (Tabela 
1). De forma pontual, são observadas formas amigdaloidais associadas com arenito, formando estruturas vítreas, semelhante ao observado na região por Petri e Fulfaro (1983) e Belliene et al. (1986).

Tabela 1. Declive, altitude, uso, vegetação e material de origem dos perfis analisados nas topossequências (VRO e VSO).

\begin{tabular}{|c|c|c|c|c|c|}
\hline Perfil & Declive & Altitude & Uso & Vegetação & Material de origem \\
\hline & $\%$ & $\mathrm{~m}$ & & & \\
\hline \multicolumn{6}{|c|}{ VRO - vertente relevo ondulado } \\
\hline$P 1^{(1)}$ & 2 & 463 & preservação permanente & mata estágio intermediário & basalto vesicular e mat, coluvial \\
\hline $\mathrm{P} 2$ & 20 & 470 & reserva legal & mata estágio intermediário & basalto vesicular e amigdaloidal \\
\hline P3 & 4 & 492 & agricultura & culturas anuais & basalto vesicular e amigdaloidal \\
\hline P4 & 15 & 513 & agricultura & culturas anuais & basalto vesicular e amigdaloidal \\
\hline P5 & 4 & 532 & agricultura & culturas anuais & basalto fanerítico \\
\hline P6 & 5 & 542 & agricultura & culturas anuais & basalto fanerítico e arenito \\
\hline P7 & 2 & 548 & agricultura & culturas anuais & basalto fanerítico e arenito \\
\hline P8 & 5 & 538 & agricultura & culturas anuais & basalto fanerítico e arenito \\
\hline \multicolumn{6}{|c|}{ VSO - vertente relevo suave ondulado } \\
\hline P1 & 10 & 472 & pecuária & pastagem plantada & basalto fanerítico \\
\hline $\mathrm{P} 2$ & 8 & 488 & agricultura & culturas anuais & basalto fanerítico \\
\hline P3 & 6 & 513 & agricultura & culturas anuais & basalto fanerítico \\
\hline P4 & 5 & 525 & agricultura & culturas anuais & basalto fanerítico e arenito \\
\hline P5 & 2 & 530 & agricultura & culturas anuais & basalto fanerítico e arenito \\
\hline
\end{tabular}

(1) Sequência dos pefis da parte mais baixa para a mais alta.

Fonte: Elaboração dos autores.

Considerando, neste caso, que as feições do relevo decorrem dos eventos magmáticos que geram segregação, as rochas originadas podem apresentar comportamento diferenciado frente ao intemperismo e às alterações no relevo. Como no local do estudo foram verificadas formas vesiculares e amigdaloidais, concomitante com relevo em degraus, há evidencia da sobreposição dos derrames e da diferenciação magmática. Tal fato já havia sido observado em outras áreas de basalto, por Thomaz (2008) em Guarapuava (PR) e Nascimento e Gorayeb (2004), no noroeste do Ceará (CE). Devido as variações do basalto, ocorrem variações de resistência ao intemperismo e à ação da erosão, portanto, com menor intensidade de desenvolvimento do solo e formação de Neossolos Regolíticos, em relevo relativamente plano. Isso porque, os basaltos amigdaloidais e vesiculares nesta área se caracterizam por apresentar amigdalas e vesículas preenchidaspor quartzo e epídoto, o que justifica sua maior resistência ao intemperismo (SILVA, 1991).

Os processos erosivos e de intemperismo, atuando em materiais diferenciados apresentam intensidade e velocidade de formação dos solos distintas, interagindo com as diversas formas de relevo. As feições côncavas e convexas do segmento inferior da VRO (Figura 2) resultam de diferenças no material de origem e relevo, em função de processos de dinâmica interna, e não apenas pela ação dos processos erosivos como relatado por Guerra e Cunha (2009).

No segmento superior da VRO é observado relevo uniforme apresentando-se suave ondulado e tendo como material de origem basalto (Tabela 
1). Nesse segmento os solos são mais profundos e desenvolvidos, no entanto no segmento inferior da VRO ocorre transição de Neossolo para Cambissolo e, finalmente para Nitossolo, na parte mais alta e de relevo suave ondulado. Ademais, está seção da topossequencia apresenta resquícios do Arenito Caiuá, visto que as formações Serra Geral e Caiuá estão em contato (MAACK, 2001; 2002). No entanto, o arenito foi exumado e os solos formados tem influência predominante do material basáltico e menor do arenito suprajacente. Esse fenômeno pode ser observado em vários locais na região, onde ocorre $\mathrm{o}$ arenito nas partes mais altas, tal como na cidade de Bela Vista do Paraíso, PR (22 $2^{\circ} 55^{\prime} \mathrm{S}$; 51 $\left.{ }^{\circ} 13^{\prime} \mathrm{O}\right)$.

$\mathrm{Na}$ VSO, onde não há diferenciações no basalto, mas apenas contribuição do arenito na parte superior da vertente, o relevo é suave, tendo maior declividade apenas próximo ao curso d'água. Nesta topossequencia a composição pedológica é mais uniforme e com pequenas variações (Figura 3).

A condição inicial do relevo da VSO, aliada ao material de rápido intemperismo e em condições propícias ao intemperismo em relação ao encontrado na VRO, pode explicar o maior grau de pedogênese. Ademais, na VRO o basalto amigdaloide aflora em áreas de maior declividade, favorecendo a erosão. $\mathrm{Na}$ VSO, mesmo considerando sua textura mais afanítica, os solos se desenvolvem em superfície mais aplainada, favorecendo maior percolação vertical e menores perdas horizontais laterais, ou seja, estes solos podem ter evoluído por um tempo maior, resistindo mais a ação dos processos erosivos. Também é notável a diferença quanto ao sistema de drenagem dos dois compartimentos da vertente VRO e na VSO. Na parte mais alta e plana da VRO e na VSO há poucas ravinas e nascentes. Já no segmento inferior da VRO o relevo é diferenciado, sendo observada numerosa rede de ravinas e nascentes, onde os solos são rasos, fato também já observado por Demattê e Demetrio (1996) em solos desenvolvidos de rochas vulcânicas ácidas na região de Guarapuava (PR).
O relevo ondulado decorre da dinâmica interna e da sucessão dos eventos magmáticos, como também observado por Thomaz (2008) em uma vertente em área de basalto no município de Guarapuava (PR). Assim, esse processo referente ao material de origem teria definido o relevo e influenciado a formação dos solos, além da composição do substrato rochoso e suas características físicas, reduzindo a intensidade de erosão e a ação do intemperismo. Portanto, os processos geomorfológicos de dinâmica interna foram tão importantes quanto o intemperismo e os processos erosivos na definição do relevo e na pedogênese.

\section{Morfologia do solo}

Quanto à profundidade dos solos (Tabela 2), os quatro primeiros perfis da VRO são rasos e não possuem limitações de drenagem e retenção de água. Nos demais perfis, nas duas vertentes os solos são profundos e não têm tais limitações.

Estudando a morfologia dos solos foi observada presença de um horizonte $\mathrm{Bt}$ logo após um horizonte $\mathrm{A}$ ou $\mathrm{AB}$, o qual lembra as características de um horizonte $\mathrm{B}$ nítico, principalmente com relação à cerosidade. Nesse sentido, foram denominados $\mathrm{B}$ nítico (Bn) e demais subdivisões, sendo o Bn1 o horizonte nítico diagnóstico propriamente dito. Exceto no perfil 1 da VSO, onde todos os subhorizontes apresentam atributos de Bn.

A disposição e espessura dos horizontes nos solos variam com a posição na vertente. A espessura do horizonte $\mathrm{Bn}$ varia de $0,51 \mathrm{~m}$ (VRO, P8) até 1,02 m (VSO P5) (Tabela 2 e Figuras 2 e 3). O Perfil 8 da VRO, apresentou a menor espessura de horizonte Bn e se encontra no topo da vertente em relevo suave ondulado. Estas condições propiciaram maior desenvolvimento do solo, com ocorrência de horizonte identificado como Bw em profundidade. Nessa área, a formação de horizonte Bt não foi tão expressiva. 
Tabela 2. Descrição dos perfis e identificação dos solos até o $4^{\circ}$ nível categórico nas topossequências (VRO e VSO).

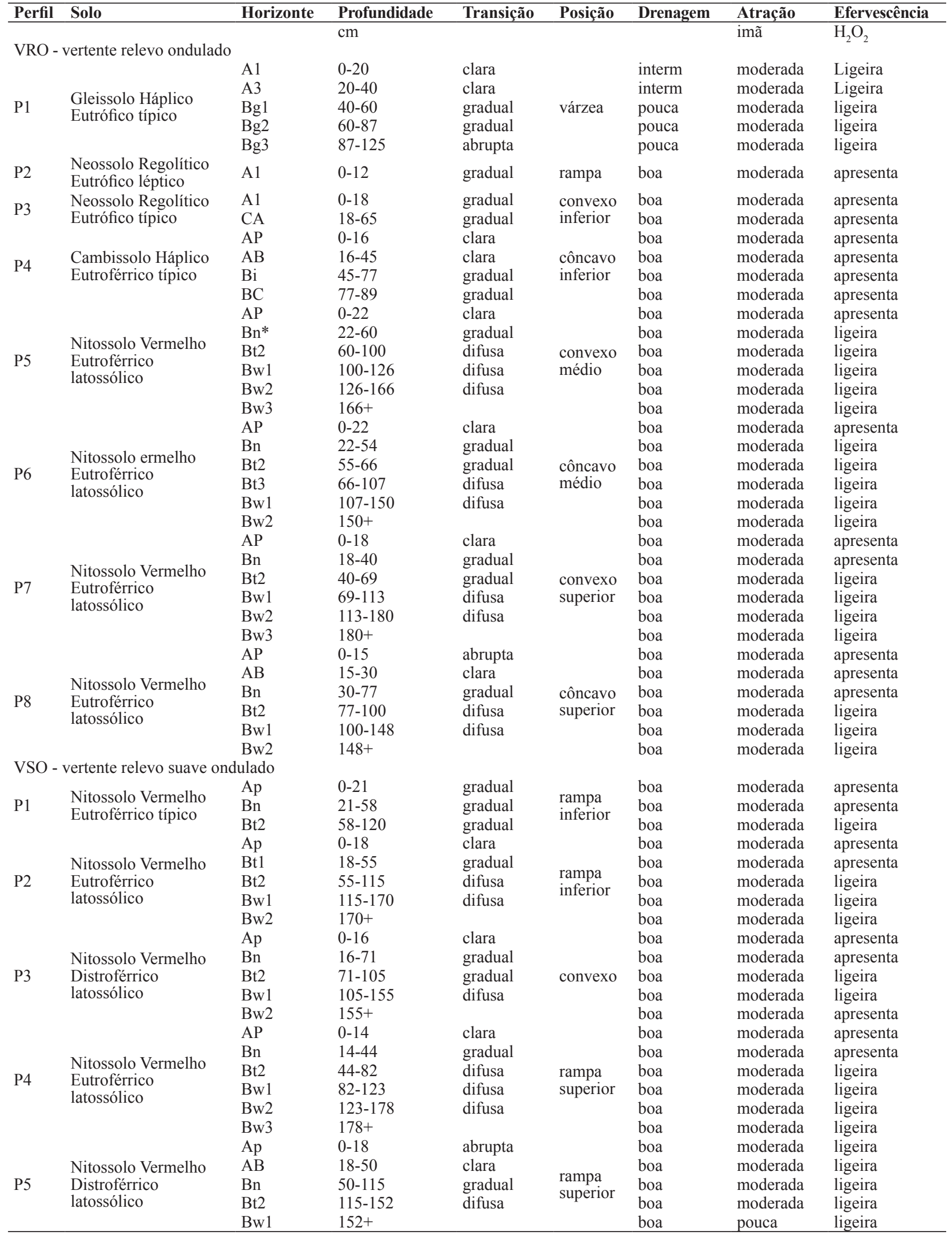

$\mathrm{Bi}-\mathrm{B}$ incipiente, ${ }^{*}$ Horizonte nítico diagnóstico.

Fonte: Elaboração dos autores. 
O Perfil 1 da VSO apresentou aumento da cerosidade nas unidades estruturais, provavelmente, por se apresentar na parte inferior da vertente, este teria recebido material iluvial translocado lateralmente em suspensão. Igualmente ao $\mathrm{Bn}$, a profundidade do Bw é variável, iniciando na profundidade de $0,69 \mathrm{~m}$ no P8 da vertente VRO e 1,52 m no P5 da VSO, devido às condições já mencionadas.

As diferenças de espessura observadas nos Bn são devido à intensidade e duração do processo pedogenético. Desta forma, na transição entre Bn e Bw, é observado horizonte com característica onde possivelmente estaria ocorrendo alterações, identificado nos Nitossolos, como um sub-horizonte com características morfológicas variadas. Devido a esse horizonte de transição, a distinção entre os limites entre Bn e Bw nem sempre é clara, ocorrendo transição de forma difusa (Tabela 2).

A formação de Latossolos requer longo período de tempo ou elevada intensidade de intemperização e menor resistência dos materiais de origem, assim, a formação do $\mathrm{B}$ nítico seria um processo mais recente e cuja intensidade é controlada pelo relevo. Deve-se considerar também que o manejo pode estar influenciando nesses processos, pois são solos agricultáveis (Tabela 1).

Quanto à estrutura, no Gleissolo (VRO, P1) é observada estrutura apenas no horizonte superficial (Tabela 3), sendo que no horizonte $\mathrm{A}_{1}$, esta é maciça, Já no horizonte diagnóstico $(\mathrm{Bg})$ e no $\mathrm{A} 3$ não há uma estrutura definida.

Os horizontes diagnósticos na sua maioria apresentam estrutura em blocos angulares (Tabela 3). Nos horizontes $\mathrm{Bw}$ ocorre estrutura predominante de grau forte e granular, com presença de pequena quantidade de blocos subangulares, principalmente nos horizontes que sucedem o Bt. Tais diferenças auxiliam na identificação e na delimitação dos horizontes Bt e Bw.

Outro aspecto relacionado ao tipo de solo e sua formação é a cor. Nos Neossolos (P2 e P3 VRO, Tabela 3), diferindo do que normalmente seria um matiz predominante vermelho, observa-se uma coloração acinzentada escura. Essa cor escura poderia ser explicada pela presença de matéria orgânica (LACERDA et al., 2008); no entanto, avaliando os teores de C desses perfis (Tabela 4), nota-se que estes não apresentam teores que permitam a predominância da cor bruna sobre o matiz vermelho. Os mesmos Autores observaram a cor bruna e outras características típicas de Horizonte A chernozênico em rocha básica, enquadrando como Chernossolos; entretanto, no caso dos solos analisados, enquadrálos como Chernossolo segundo o SBCS não seria possível principalmente devido à pequena espessura do horizonte A (A fraco). Nos demais horizontes, foi verificado matriz com predominância do vermelho comum aos solos de basalto.

A coloração predominante vermelha observada é em virtude da oxidação do Fe(II) com o intemperismo, dentre outros elementos metálicos presente na rocha. Como nos solos jovens onde se observa coloração acinzentada, o intemperismo do material primário é menor, sendo observado muito material primário intacto, a cor pode advir da incompleta oxidação dos compostos metálicos contido na rocha, além de características diferenciadas do material de origem onde se encontram esses solos (Tabela 1).

Desta forma, foi observada cor praticamente uniforme nos solos mais profundos, apresentando matiz com predominância do vermelho (10R e 2,5 YR), havendo apenas algumas variações no tom (valor e croma) (Tabela 3), cores semelhante às observadas por Ghidin et al. (2006) e Vidal-Torrado et al. (1999) para solos derivados de basalto. Além disso, constata-se a presença de hematita, como óxido de ferro dominante.

Em relação à atração magnética, esta foi considerada moderada, em relação aos solos derivados do basalto da região de Londrina-PR ( $\left.23^{\circ} 19^{\prime} \mathrm{S} ; 51^{\circ} 10^{\prime} \mathrm{O}\right)$. Lacerda et al. (2008) em trabalho com rochas básicas e ultrabásicas relatam a formação de horizonte $\mathrm{B}$ nítico com matiz com predominância do vermelho e observa atração magnética forte. Isso ocorre possivelmente devido a menor concentração de ferro nos basaltos.

Em relação à cerosidade, nos Bt esta é variável, no entanto nos $\mathrm{Bt}_{1}$ (considerados $\mathrm{B}$ nítico diagnóstico) observa-se cerosidade forte a moderada e comum (Tabela 3), caracterizando-os como um B nítico. Assim, muitos dos atributos morfológicos observados, têm alguma relação com a posição na vertente e a espécie de Basalto. 
Tabela 3. Descrição morfológica dos perfis e horizontes dos solos nas topossequências (VRO e VSO).

\begin{tabular}{|c|c|c|c|c|c|c|c|c|c|c|c|}
\hline \multirow[t]{2}{*}{ Perfil } & \multirow[t]{3}{*}{ Horizonte } & \multirow[t]{3}{*}{ Cerosidade } & \multicolumn{2}{|c|}{ Cor (Munsell) } & \multicolumn{2}{|c|}{ Estrutura } & \multicolumn{2}{|c|}{ Consistência } & \multirow{2}{*}{\multicolumn{2}{|c|}{$\frac{\text { Argila Silte }}{\mathrm{g}, \mathrm{Kg}^{-1}}$}} & \multirow[t]{2}{*}{ Areia } \\
\hline & & & seco & úmido & grau & classe & seco & molhada & & & \\
\hline & & & VRO & vertente rele & o ondu & & & & & & \\
\hline \multirow[t]{5}{*}{ P1 } & A1 & $* *$ & 7,5 YR 4/4 & 7,5 YR $3 / 2$ & forte & peq, bl, Subang & ext, duro & $\mathrm{m}, \mathrm{pl}, \mathrm{m}, \mathrm{peg}$ & 830 & 120 & 50 \\
\hline & A3 & - & 7,5 YR $4 / 4$ & $5 \mathrm{YR} 4 / 2$ & $* * *$ & sem, mac,coe, & ext, duro & $\mathrm{m}, \mathrm{pl}, \mathrm{m}, \mathrm{peg}$ & 870 & 100 & 30 \\
\hline & $\mathrm{Bg} 1$ & - & $7,5 \mathrm{YR} 4 / 4$ & 7,5YR 3/2 & - & sem, mac,coe, & ext, duro & $\mathrm{m}, \mathrm{pl}, \mathrm{m}, \mathrm{peg}$ & 740 & 130 & 130 \\
\hline & $\mathrm{Bg} 2$ & - & 7,5 YR 4/6 & $5 \mathrm{YR}^{3} / 4$ & - & sem, mac,coe, & ext, duro & $\mathrm{m}, \mathrm{pl}, \mathrm{m}, \mathrm{peg}$ & 705 & 100 & 195 \\
\hline & $\mathrm{Bg} 3$ & - & $10 \mathrm{YR} 4 / 2$ & $7,5 \mathrm{YR} 3 / 2$ & - & sem, mac,coe, & ext, duro & $\mathrm{m}, \mathrm{pl}, \mathrm{m}, \mathrm{peg}$ & 800 & 110 & 90 \\
\hline $\mathrm{P} 2$ & A1 & - & $5 \mathrm{YR} 4 / 2$ & 5 YR $3 / 2$ & forte & peq, bl, subang & duro & pl, peg, & 600 & 170 & 230 \\
\hline \multirow[t]{2}{*}{ P3 } & Ap & - & $5 Y R 3 / 2$ & $5 Y R 3 / 2$ & forte & peq, gr, maciça & ext, duro & pl, peg, & 600 & 145 & 255 \\
\hline & $\mathrm{CA}$ & - & 5 YR $6 / 2$ & 2,5 YR $3 / 2$ & - & sem, mac,coe, & ext, duro & pl, peg, & - & - & - \\
\hline \multirow{4}{*}{ P4 } & Ap & - & $2,5 / 2$ YR $2,5 / 4$ & $10 \mathrm{R} 3 / 3$ & forte & peq, bl, subang & $\mathrm{m}$, duro & $\mathrm{pl}, \mathrm{m}$, peg & 700 & 120 & 180 \\
\hline & $\mathrm{AB}$ & - & 2,5 YR $2,5 / 4$ & $10 \mathrm{R} 3 / 3$ & forte & peq, bl, subang & ext, duro & $\mathrm{pl}, \mathrm{m}$, peg & 765 & 190 & 45 \\
\hline & $\mathrm{Bi}$ & mod comum & $2,5 \mathrm{YR} 3 / 4$ & $10 \mathrm{R}^{3} / 4$ & forte & peq, bl, ang, & ext, duro & $\mathrm{pl}, \mathrm{m}$, peg & 810 & 80 & 110 \\
\hline & $\mathrm{BC}$ & fraca comum & 2,5 YR $3 / 4$ & 10R $3 / 3$ & forte & peq, bl, ang, & ext, duro & $\mathrm{pl}, \mathrm{m}$, peg & 885 & 80 & 35 \\
\hline P5 & $\mathrm{Ap}$ & - & $10 \mathrm{R} 3 / 3$ & $2,5 \mathrm{YR}^{3} / 4$ & forte & med, bl, ang, & $\mathrm{m}$, duro & pl, peg, & 720 & 165 & 115 \\
\hline & $\mathrm{Bt} 1^{*}$ & mod comum & $10 \mathrm{R} 4 / 6$ & $10 \mathrm{R} 4 / 4$ & forte & peq, bl, ang, & $\mathrm{m}$, duro & $\mathrm{pl}, \mathrm{m}, \mathrm{peg}$ & 820 & 65 & 115 \\
\hline & Bt2 & fraca comum & $2,5 \mathrm{YR} 4 / 4$ & $10 \mathrm{R}^{3} / 4$ & forte & peq, bl, sub & m,duro & $\mathrm{pl}, \mathrm{m}, \mathrm{peg}$ & 790 & 75 & 135 \\
\hline & Bw1 & - & $10 \mathrm{R} 4 / 4$ & $10 \mathrm{R}^{3} / 4$ & forte & m, peq, gr, mac, & duro & $\mathrm{pl}$, peg, & 875 & 60 & 65 \\
\hline & Bw2 & - & $10 \mathrm{R} 4 / 6$ & $10 \mathrm{R}^{3} / 4$ & forte & $\mathrm{m}$, peq, gr, mac & duro & pl, peg, & 795 & 135 & 70 \\
\hline & Bw3 & - & 2,5 YR $3 / 6$ & $10 \mathrm{R}^{3} / 4$ & forte & $\mathrm{m}$, peq, gr, mac & lig, duro & pl, peg, & 800 & 45 & 155 \\
\hline P6 & $\mathrm{Ap}$ & - & 2,5 YR $3 / 4$ & $10 \mathrm{R} 3 / 2$ & forte & peq, bl, ang, & $\mathrm{m}$, duro & $\mathrm{pl}, \mathrm{peg}$, & 520 & 125 & 355 \\
\hline & Bt1 & mod comum & 2,5 YR $3 / 4$ & $10 \mathrm{R} 3 / 3$ & forte & peq, bl, ang, & $\mathrm{m}$, duro & $\mathrm{pl}, \mathrm{m}$, peg, & 660 & 110 & 230 \\
\hline & Bt2 & fraca comum & $2,5 \mathrm{YR} 4 / 4$ & $10 \mathrm{R}^{3} / 4$ & forte & peq, bl, ang, & $\mathrm{m}$, duro & $\mathrm{pl}, \mathrm{m}, \mathrm{peg}$ & 810 & 60 & 130 \\
\hline & $\mathrm{Bt} 3$ & fraca comum & 2,5 YR 4/4 & $10 \mathrm{R}^{3} / 4$ & forte & med, bl, sub, & duro & pl, m, peg, & 760 & 55 & 160 \\
\hline & Bw1 & - & & & forte & & & & 755 & 60 & 185 \\
\hline & Bw2 & - & $\mathrm{R} 4 / 6$ & $10 R^{3} / 4$ & forte & $\mathrm{m}$, peq, gr, mac, & lig, duro & pl, peg, & 705 & 125 & 170 \\
\hline P7 & $\mathrm{Ap}$ & - & 2,5 YR $3 / 4$ & $10 \mathrm{R} 3 / 3$ & forte & med, bl, sub, & duro & $\mathrm{pl}, \mathrm{m}, \mathrm{peg}$ & 555 & 50 & 395 \\
\hline & $\mathrm{Bt} 1$ & mod comum & 10R $3 / 6$ & $10 \mathrm{R} 3 / 3$ & forte & peq, bl, ang, & $\mathrm{m}$, duro & $\mathrm{pl}, \mathrm{m}, \mathrm{peg}$ & 670 & 100 & 230 \\
\hline & Bt2 & fraca comum & $10 \mathrm{R} 3 / 6$ & $10 \mathrm{R}^{3} / 4$ & forte & peq, bl, ang, & duro & pl, m, peg, & 765 & 85 & 150 \\
\hline & BW1 & - & $10 \mathrm{R} 4 / 4$ & $10 \mathrm{R}^{3} / 4$ & forte & $\mathrm{m}$, peq, gr, mac, & duro & $\mathrm{pl}, \mathrm{m}, \mathrm{peg}$ & 710 & 90 & 200 \\
\hline & Bw2 & - & $10 \mathrm{R} 4 / 6$ & $10 \mathrm{R}^{3} / 4$ & forte & m 1 & lig, duro & pl, peg, & 695 & 75 & 230 \\
\hline & BW3 & - & $10 \mathrm{R} 4 / 6$ & $10 \mathrm{R}^{3} / 4$ & forte & $\mathrm{m}$, peq, & macio & pl, peg, & 690 & 75 & 235 \\
\hline P8 & Ap & - & 2,5 YR $3 / 4$ & $10 \mathrm{R} 3 / 3$ & forte & peq, gran, mac, & duro & $\mathrm{pl}, \mathrm{m}, \mathrm{peg}$ & 730 & 30 & 240 \\
\hline & $\mathrm{AB}$ & - & $2,5 \mathrm{YR} 4 / 4$ & $10 \mathrm{R} 3 / 3$ & forte & med, bl, ang, & $\mathrm{m}$, duro & pl, m, peg, & 685 & 85 & 230 \\
\hline & Bt1 & mod comum & $10 \mathrm{R} 4 / 6$ & $10 \mathrm{R}^{3} / 4$ & forte & med, bl, ang, & ext, duro & pl, m, peg, & 775 & 135 & 90 \\
\hline & $\mathrm{Bt} 2$ & fraca comum & $10 \mathrm{R} 4 / 4$ & $10 \mathrm{R}^{3} / 4$ & forte & peq, bl, ang & $\mathrm{m}$, duro & $\mathrm{pl}, \mathrm{m}, \mathrm{peg}$ & 795 & 70 & 135 \\
\hline & Bw1 & - & 10R 4/6 & $10 \mathrm{R} 3 / 6$ & forte & $\mathrm{m}$, peq, gr, mac, & lig, duro & pl, peg, & 710 & 60 & 230 \\
\hline & Bw2 & - & 10R 4/6 & $10 \mathrm{R}^{3} / 4$ & forte & $\mathrm{m}$, peq, gr, mac, & macio & $\mathrm{pl}$, peg, & 795 & 40 & 165 \\
\hline & & & VSO - & onte & 列 & lulado & & & & & \\
\hline P1 & Ap & fraca comum & $10 \mathrm{R} 3 / 3$ & 10R $3 / 2$ & forte & med, bl, ang, & $\mathrm{m}$, duro & peg, & 805 & 120 & 75 \\
\hline & Bt1 & forte comum & $10 \mathrm{R} 3 / 4$ & $10 \mathrm{R} 3 / 3$ & forte & peq, bl, & Iro & eg, & 910 & 60 & 30 \\
\hline & Bt2 & mod comum & 10R 3/6 & $10 \mathrm{R} 3 / 3$ & forte & peq, bl, ang, & $\mathrm{m}$, duro & pl, m, peg, & 905 & 50 & 45 \\
\hline $\mathrm{P} 2$ & Ap & - & $10 \mathrm{R} 3 / 4$ & $10 \mathrm{R} 3 / 2$ & forte & peq, bl, sub, & $\mathrm{m}$, duro & pl, peg, & 820 & 120 & 60 \\
\hline & Bt1 & mod comum & $10 \mathrm{R} 3 / 6$ & $10 \mathrm{R} 3 / 3$ & forte & peq, bl, ang, & $\mathrm{m}$, duro & $\mathrm{pl}, \mathrm{m}, \mathrm{peg}$ & 915 & 50 & 35 \\
\hline & Bt2 & fraca comum & $10 \mathrm{R} 3 / 6$ & $10 \mathrm{R} 3 / 3$ & forte & peq, bl, ang, & duro & pl, m, peg, & 910 & 50 & 40 \\
\hline & Bw1 & - & 10R $3 / 6$ & $10 \mathrm{R} 3 / 3$ & forte & $\mathrm{m}$, peq, gr, mac, & duro & $\mathrm{pl}, \mathrm{peg}$ & 925 & 40 & 35 \\
\hline & Bw2 & - & 10R 3/6 & $10 \mathrm{R} 3 / 3$ & forte & $\mathrm{m}$, peq, gr, mac, & lig, duro & pl, peg, & 915 & 50 & 35 \\
\hline P3 & Ap & - & $10 \mathrm{R} 3 / 6$ & $10 \mathrm{R} 3 / 3$ & forte & peq, gr, mac, & $\mathrm{m}$, duro & $\mathrm{pl}, \mathrm{m}, \mathrm{peg}$ & 790 & 110 & 100 \\
\hline & Bt1 & mod comum & $3 / 6$ & $3 / 3$ & forte & peq, bl, ang, & $\mathrm{m}$, duro & $\mathrm{pl}, \mathrm{m}, \mathrm{peg}$ & 870 & 80 & 50 \\
\hline & Bt2 & fraca comum & 10R $3 / 6$ & $10 \mathrm{R} 3 / 3$ & forte & peq, bl, sub, & uro & pl, m, peg, & 865 & 110 & 25 \\
\hline & Bw1 & fraca comum & $10 \mathrm{R} 3 / 6$ & $10 \mathrm{R} 3 / 3$ & forte & $\mathrm{m}$, peq, gr, mac, & lig, duro & $\mathrm{pl}, \mathrm{peg}$ & 860 & 85 & 55 \\
\hline & Bw2 & - & 2,5 YR $3 / 6$ & $10 \mathrm{R} 3 / 4$ & forte & m, peq, gr, mac, & uro & pl,peg & 865 & 110 & 25 \\
\hline $\mathrm{P} 4$ & Ap & - & $2,5 \mathrm{YR} 3 / 4$ & $10 \mathrm{R} 3 / 3$ & forte & med, bl, ang, & $\mathrm{m}$, duro & pl, m, peg, & 755 & 120 & 125 \\
\hline & Bt1 & mod comum & 2,5 YR $3 / 6$ & $10 \mathrm{R} 3 / 3$ & forte & peq, bl, sub, & $\mathrm{m}$, duro & peg, & 840 & 65 & 95 \\
\hline & Bt2 & fraca comum & $10 \mathrm{R} 3 / 6$ & $10 \mathrm{R} 3 / 4$ & forte & peq, bl, sub, & m, duro & pl, m, peg, & 890 & 70 & 40 \\
\hline & Bw1 & fraca comum & 10R $3 / 6$ & $10 \mathrm{R} 3 / 4$ & forte & peg, bl, sub, & duro & $\mathrm{pl}$, peg, & 890 & 75 & 35 \\
\hline & Bw2 & - & 10R $3 / 6$ & $10 \mathrm{R} 3 / 4$ & forte & $\mathrm{m}$, peq, gr, mac, & lig, duro & pl, peg, & 880 & 85 & 35 \\
\hline & Bw3 & - & $10 \mathrm{R} 3 / 6$ & $10 \mathrm{R} 3 / 4$ & forte & m, peq, gr, mac, & lig, duro & pl, peg, & 880 & 70 & 50 \\
\hline P5 & Ap & - & 10R $3 / 6$ & $10 \mathrm{R} 3 / 3$ & forte & méd, bl, ang, & ext, duro & pl, m, peg, & 810 & 50 & 140 \\
\hline & $\mathrm{AB}$ & - & $10 \mathrm{R} 3 / 6$ & $10 \mathrm{R} 3 / 3$ & forte & méd, bl, ang, & duro & pl, m, peg, & 795 & 55 & 150 \\
\hline & Bt1 & mod, comum & $10 \mathrm{R} 3 / 6$ & $10 \mathrm{R} 3 / 3$ & forte & peq, bl, ang, & $\mathrm{m}$, duro & pl, m, peg, & 800 & 50 & 150 \\
\hline & $\mathrm{Bt} 2$ & fraca comum & $10 \mathrm{R} 3 / 6$ & $10 \mathrm{R} 3 / 3$ & forte & peq, bl, sub, & duro & $\mathrm{pl}, \mathrm{m}, \mathrm{peg}$ & 790 & 35 & 175 \\
\hline & Bw1 & - & $10 \mathrm{R} 3 / 6$ & $10 \mathrm{R} 3 / 3$ & forte & m, peq, gr, mac, & lig, duro & pl, peg, & 880 & 35 & 85 \\
\hline
\end{tabular}

$\mathrm{Bi}$ - B incipiente, ${ }^{*} \mathrm{~B}$ nítico diagnóstico, ${ }^{* *}$ Atributo ausente, ${ }^{* * *}$ Não avaliado, Peq, (pequena), m, peq,: muito pequena, med: média, bl, ang,: blocos angulares; bl, subang,: blocos subangulares; gr,: granular; gr, gru,:granular em grumos; m, duro: muito duro; ext, duro: extremamente duro; lig, duro: ligeiramente duro; pl,: plástico; m, pl,: muito plástico; lig, Pl,: ligeiramente plástico; pg,: pegajoso; lig, pg,: ligeiramente pegajoso; m, peg,: muito pegajoso.

Fonte: Elaboração dos autores. 
Tabela 4. Atributos químicos dos horizontes dos solos nas topossequências (VRO e VSO).

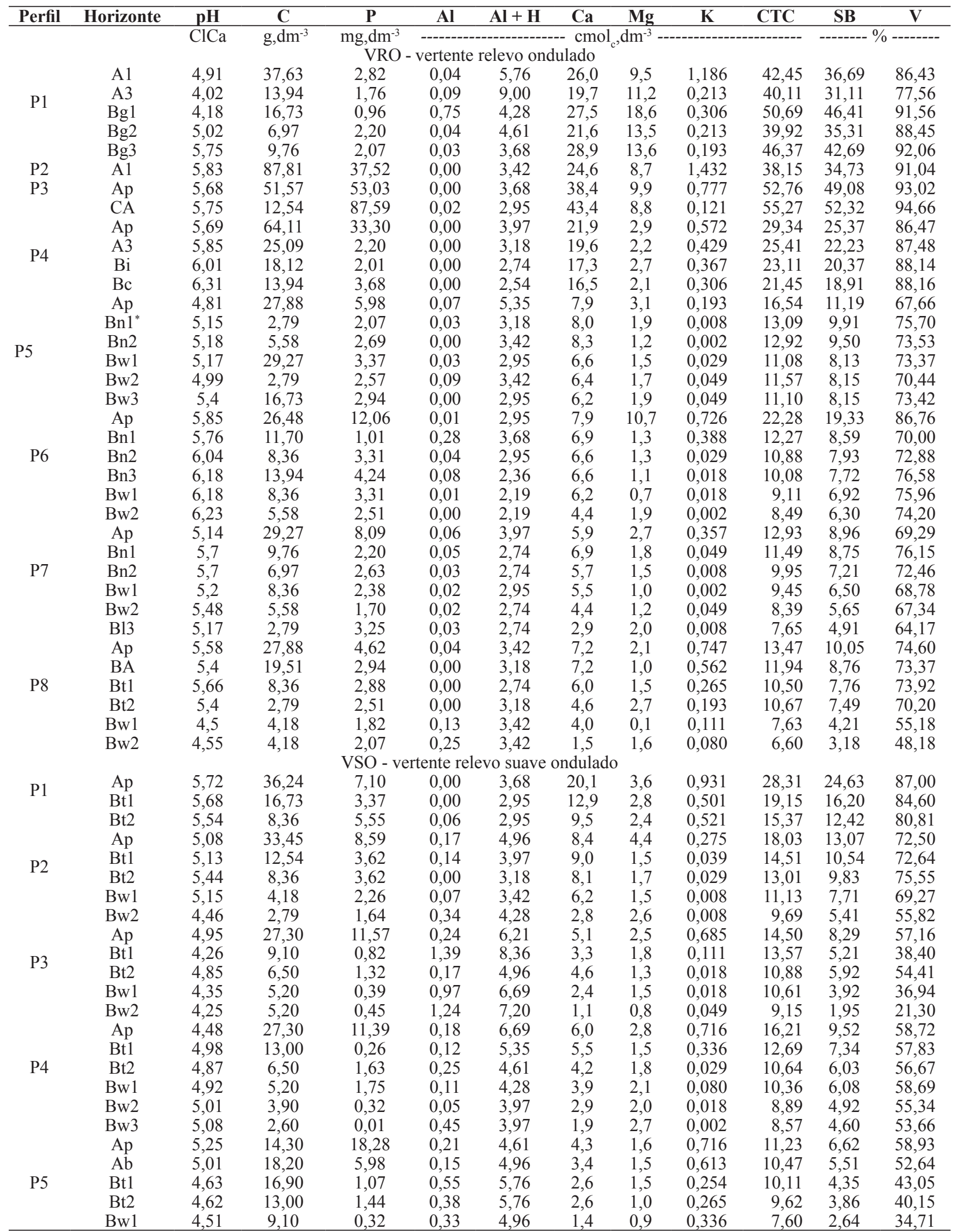

$\mathrm{Bi}-\mathrm{B}$ incipiente, ${ }^{*} \mathrm{~B}$ nítico diagnóstico.

Fonte: Elaboração dos autores. 


\section{Atributos químicos}

Com relação aos atributos químicos observados na Tabela 4, é possível verificar a diferença nos teores de bases entre os horizontes do seguimento inferior da VRO e os demais perfis das VRO e VSO. Também a riqueza química pode ser associada à evolução do solo e sua origem. Os solos mais jovens por sofrerem menores perdas, preservam boa parte destes. Porém um material de origem mais rico poderá formar, em conseqüência, solos também mais ricos quimicamente.

A grande diferença na composição química dos solos do seguimento inferior da VRO evidencia que há diferenças na composição da rocha, haja vista diferenças expressivas de bases $\left(\mathrm{Ca}^{2+} \mathrm{e}\right.$ $\mathrm{Mg}^{2+}$ ). O material mais rico, principalmente em bases, poderia estar em forma de minerais, preenchendo as amígdalas da rocha, visto que é muito comum se encontrar Zeólitas e Calcita nas amigdalas. Tal variação nos teores de bases não é observada de forma expressiva na VSO, a qual tem como material de origem basalto afanítico em toda vertente (Tabela 1).

Os Neossolos, embora possuam fertilidade química (Tabela 4), sua pequena profundidade impede uma boa retenção e infiltração de água, não possibilitando condições para um bom desenvolvimento radicular, consistindo em solos limitantes principalmente para culturas perenes. Além disso, estes solos, apesar de sua limitação física, são ricos em bases.

Assim, observa-se vários aspectos que corroboram o pressuposto de que a diferença de fertilidade química nos solos ao longo das vertentes, principalmente na VRO, está relacionada ao material de origem observado neste local.
O Gleissolo, encontrado em área de várzea, que pode ter origem a partir de material alóctone, apresentou-se com alta saturação por bases. Guerra e Cunha (2009) mencionam que os Gleissolos são solos de planícies aluviais, várzeas e depressões; podem ser distróficos ou eutróficos. Os eutróficos, são geralmente relacionados a solos férteis localizados nas encostas circunvizinhas, e que são transportados pelos agentes fluviais, tal como os solos jovens encontrados no seguimento inferior da VRO (Tabela 4). Assim, esses solos apesar de sua limitação física são ricos em bases.

Embora trabalhos mostrem que os solos de sopé devido a contribuição dos solos do topo, seriam mais ricos em bases (eutróficos) (CAMPOS et al., 2011), os Neossolos localizados em local de relevo acentuado e sob a influência da erosão, também se apresentam com elevado teor de bases. Assim, a riqueza química observada no Gleissolo, não foi em detrimento dos solos ao redor, pelo contrário, todos se apresentam com elevado teor de bases, provavelmente devido a alcalinidade da rocha basáltica.

\section{Mineralogia da fração argila}

Nos gráficos de difração de Raios-X de horizontes da VSO, pode ser observado padrão bem distinto de picos entre um horizonte $\mathrm{Bw}$ e os horizontes Bt (Figura 4). O mesmo padrão é observado nos $\mathrm{Bw}$ da VRO. Entre o $\mathrm{B}$ nítico característico e o sub-horizonte de transição para Bw há pequena diferença. Nos Bw é observada uma grande quantidade de material primário resistente ao intemperismo, tal como o quartzo que seria de predominância do arenito. 
Figura 4. Difratograma da fração argila dos Raios X dos conjuntos VSO e VRO.
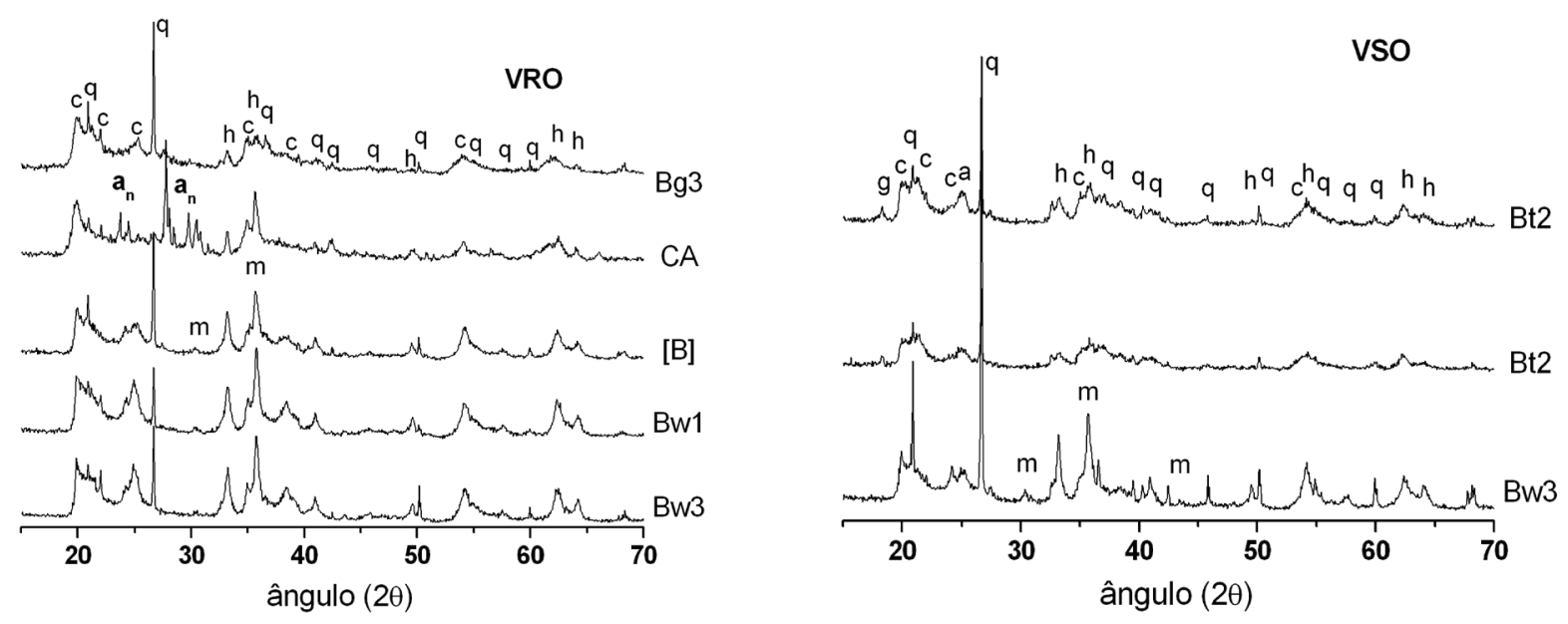

As letras representam: (a) anatase, (an) anortita, (c) caulinita, (g) gibsita, (h) hematita, (m) magnetita e (q) quartzo.

Fonte: Elaboração dos autores.

$\mathrm{Na}$ análise quantitativa com os valores relativos dos minerais, o perfil de Gleissolo, apresentou como mineral dominante a Kalovita ( $\mathrm{Zn}$ ) com $39 \%$ (porção que pode indicar um depósito de Zn), seguido da Hematita (19\%), Cristalobalita (16\%) e Quartzo (16\%) não sendo a Caulinita expressiva. No perfil de Neossolo a Anortita representou a maior proporção com 50\%. seguido de outros minerais primários (31\%), Hematita (6\%) e Magnetita (12\%), sem expressiva presença de Quartzo. Já no Cambissolo, há 47\% de Caulinita $24 \%$ de Quartzo e $11 \%$ de Hematita. Para os Nitossolos das duas vertentes há predominância de Caulinita e Quartzo, com a presença variável de Hematita.

Embora ocorram minerais primários na fração argila dos solos pouco desenvolvidos, há que se considerar que em solos jovens e com presença de cascalho a maioria dos minerais primários se concentra na fração grosseira. Assim, a quantidade esperada de material primário nessa fração é maior. A ocorrência de grande quantidade de materiais primários e de fácil intemperismo evidenciaria também a pobre drenagem ou a baixa retenção de água desses solos localizados no seguimento inferior da VRO.
Considera-se o Gleissolo semelhante aos Neossolos, visto que os Neossolos contribuem com material para a formação destes. Há, porém, alteração e reações próprias do processo de hidromorfismo levando a diferenciação de sua composição.

Na vertente VRO os perfis de Neossolo e Gleissolo foram os únicos a não apresentarem quantidades significativas de Caulinita, predominando nestes, respectivamente, a Kalovita e a Anotita. Tal fato é esperado visto que a Caulinita é uma espécie de argila de solos intemperizados de clima tropical. Mesmo com a predominância de alguns minerais a Caulinita é o mineral dominante na fração argila das duas topossequências.

Ghidin et al. (2006) em estudo de topossequência, também verificou que a posição dos perfis na paisagem influencia a mineralogia da fração argila devido à dinâmica do intemperismo influenciado pelo caminhamento da água, desenvolvida em cada porção desta. Nas vertentes estudadas, a diferenciação na mineralogia se daria devido a estádio de evolução de cada solo e principalmente, ao material formador.

Os dois Bt analisados da VSO, foram os únicos a apresentar em sua composição o argilomineral 
Caulinita e o óxido Gibbsita. Em estudo sobre LATOSSOLOS, Ferreira, Fernandes e Curi (1999) verificou que a Caulinita e Gibbsita foram os constituintes mineralógicos que maior influenciaram as propriedades físicas do solo. Além disso, os LATOSSOLOS cauliníticos apresentaram diferenças em seus atributos físicos quando comparados com solos com maior presença de Gibsita (SCHAEFER; FABRIS; KER, 2008).

\section{Conclusões}

A dinâmica interna e o processo de segregação magmática foram os principais responsáveis pelas formas de relevo e pelo tipo de rocha formada, com significativa variação do solo formado quando da ocorrência de variações em uma mesma rocha.

As formas do relevo e a diferenciação do basalto tiveram importância significativa na evolução e distribuição de solos nas vertentes estudadas.

Os solos com horizontes B nítico e B latossólico foram os que se apresentaram em maior extensão nas vertentes, sendo que sua espessura está relacionada à intensidade do processo de formação condicionado pela posição na vertente.

\section{Agradecimentos}

Aos comentários do Dr. Michel Brossard, pesquisador do Institut de Recherche Pour Le Développement, que contribuíram para enriquecer o trabalho, Ao CNPq pela concessão de bolsas.

\section{Referências}

BELLIENE, G.; COMIN-CHIARAMONTI, P.; MARQUES, L. S.; MELFI, A. J.; NARDY, A. J. R.; PAPATRECHAS, C.; PICCIRILLO, E. M.; ROISENBERG, A.; STOLFA, D. Petrogenetic aspects of acid and basaltic lavas from the Paraná Plateau (Brazil): geological, mineralogical and petrochemical relationships. Journal of Petrology, Oxford, v. 27, n. 4, p. 915-944, 1986.
BOCKHEIM, J. G.; GENNADIYEV, A. N.; HAMMER, R. D.; TANDARICH, J. P. Historical development of key concepts in pedology. Geoderma, Amsterdam, v. 124, n. 1, p. 23-36, 2005.

CAMPOS, M. C. C.; MARQUES JÚNIOR, J.; PEREIRA, G. T.; MONTANARI, R.; CAMARGO, L. A. Relações solo-paisagem em uma litossequência arenito-basalto na região de Pereira Barreto, SP. Revista Brasileira de Ciência do Solo, Viçosa, MG, v. 31, n. 3, p. 519-529, 2007.

CAMPOS, M. C. C.; RIBEIRO, M. R.; SOUZA JÚNIOR, V. S.; RIBEIRO FILHO, M. R.; COSTA, E. U. C. Segmentos de vertente e atributos do solo de uma toposseqüência na região de Manicoré, AM. Revista Ciência Agronômica, Fortaleza, v. 41, n. 4, p. 501-510, 2010.

CAMPOS, M. C. C.; RIBEIRO, M. R.; SOUZA JÚNIOR, V. S.; RIBEIRO FILHO, M. R.; SOUZA, R. V. C. C. Relações solo-paisagem em uma topossequência sobre substrato granítico em Santo Antônio do Matupi, Manicoré (AM). Revista Brasileira de Ciência do Solo, Viçosa, MG, v. 35, n. 1, p. 13-23, 2011.

COOPER, M.; VIDAL-TORRADO, P.; GRIMALDI, M. Soil structure transformations from ferralic to nitic horizons on a toposequence in southeastern Brazil. Revista Brasileira de Ciência do Solo, Viçosa, MG, v. 34, n. 5, p. 1685-1699, 2010.

DEMATTÊ, J. A. M.; DEMETRIO, V. A. Padrões de drenagem em áreas de solos desenvolvidos de rochas vulcânicas ácidas na região de Guarapuava (PR). Revista Brasileira de Ciência do Solo, Campinas, v. 20, n. 2, p. 305-311, 1996.

EMPRESA BRASILEIRA DE PESQUISA AGROPECUÁRIA - EMBRAPA. Centro Nacional de Pesquisa de Solos. Manual de métodos de análise de solo. 2. ed. Rio de Janeiro: Embrapa, 1997. 212 p.

FERREIRA, M. M.; FERNANDES, B.; CURI, N. Influência da mineralogia da fração argila nas propriedades físicas de Latossolos da região sudeste do Brasil. Revista Brasileira de Ciência do Solo, Viçosa, MG, v. 23, n. 3, p. 515-524, 1999.

GHIDIN, A. G.; MELO, V. F.; LIMA, V. C.; LIMA, J. M. J. C. Topossequencias de Latossolos originados de rochas basálticas no Paraná, II - relação entre mineralogia da fração argila e propriedades físicas do solo. Revista Brasileira de Ciência do Solo, Viçosa, MG, v. 30, n. 2, p. 307-319, 2006.

GUERRA, A. J. T.; CUNHA, S. B. Geomorfologia: uma atualização de bases e conceitos. 9. ed. Rio de Janeiro: Bertrand Brasil, 2009. 472 p. 
LACERDA, M. P. C.; QUEMÉNÉUR, J. J. G.; ANDRADE, H.; ALVES, H. M. R.; VIEIRA, T. G. C. Estudo da relação pedomorfogeológica na distribuição de solos com horizontes B textural e B nítico na paisagem de Lavras (MG). Revista Brasileira de Ciência do Solo, Viçosa, MG, v. 32, n. 1, p. 271-284, 2008.

MAACK, R. Breves notícias sobre a geologia dos estados do Paraná e Santa Catarina. Brazilian Archives of Biology and Technology, Curitiba, v. 2, p. 169-288, 2001.

Geografia física do estado do Paraná. 3. ed. Curitiba: Imprensa Oficial, 2002. 438 p.

MILNE, G. Some suggested units of classification and mapping, particularly for East African soils. Soil Research, London, v. 4, n. 2, p. 183-198, 1935.

NASCIMENTO, R. S.; GORAYEB, P. S. S. Basaltos da suíte Parapuí, Gráben Jaibaras, noroeste do Ceará: caracterização, petrografia, geoquímica e química mineral. Revista Brasileira de Geociências, São Paulo, v. 34, n. 4, p. 459-468, 2004.

PACHEPSKY, Y. A.; TIMLIN, D. J.; RAWLS, W. J. Soil water retention as related to topographic variables. Soil Science Society of America Journal, Madison, v. 65, n. 6, p. 1787-1795, 2001.

PETRI, S.; FÚlFARO, V. J. Geologia do Brasil. São Paulo: EDUSP, 1983. 631 p.

RUHE, R. V. Geomorphic surfaces and the nature of soils. Soil Science, Baltimore, v. 82, n. 6, p. 441-445, 1956.

SANTOS, A. C.; PEREIRA, M. G.; ANJOS, L. H. C.; BERNINI, T. A.; COOPER, M.; NUMMER, A. R.; FRANCELINO, M. R. Gênese e classificação de solos numa topossequência no ambiente de mar de morros do médio Vale do Paraíba do Sul, RJ. Revista Brasileira de Ciência do Solo, Viçosa, MG, v. 34, n. 4, p, 1297-1314, 2010.

SANTOS, H. G.; JACOMINE, P. K. T.; ANJOS, L. H. C.; OLIVEIRA, V. A.; OLIVEIRA, J. B.; COELHO, M.
R.; LUMBRERAS, J. F.; CUNHA, T. J. F. (Ed.). Sistema brasileiro de classificação de solos. 2. ed. Rio de Janeiro: Embrapa Solos, 2006. 316 p.

SANTOS, R. D.; LEMOS, R. C.; SANTOS, H. G.; KER, J. C.; ANJOS, L. H. C. Manual de descrição e coleta de solo no campo. 5. ed. Viçosa: SBCS, 2005. 92 p.

SCHAEFER, C. E. G. R.; FABRIS, J. D.; KER, J. C. Minerals in the clay fraction of Brazilian Latosols (Oxisols): a review. Clay Minerals, London, v. 43, n. 1, p. 137-154, 2008.

SILVA, A. C.; VIDAL-TORRADO, P.; PÉREZ, M. G.; MARTIN NETO, L.; VASQUEZ, F. M. Relações entre matéria orgânica do solo e declividade de vertentes em topossequências de Latossolos do sul de Minas Gerais. Revista Brasileira de Ciência do Solo, Viçosa, MG, v. 31, n. 5, p. 1059-1068, 2007.

SILVA, L. C. O cinturão metavulcanossedimentar brusque e a evolução policíclica das faixas dobradas proterozóicas no Sul do Brasil: uma revisão. Revista Brasileira de Geociências, São Paulo, v. 21, n. 1, p. 6073, 1991.

SOUZA JÚNIOR, J. G. A.; DEMATTÊ, J. A. M. Modelo digital de elevação na caracterização de solos desenvolvidos de basalto e material arenítico. Revista Brasileira de Ciência do Solo, Viçosa, v. 32, n. 1, p. 449456, 2008.

THOMAZ, E. L. Aspectos geomorfopedológicos de uma vertente em área de basalto no município de Guarapuava - PR. Mercator, Fortaleza, v. 7, n. 14, p. 67-85, 2008.

VIDAL-TORRADO, P.; LEPSCH, I. F.; CASTRO, S. S. Conceitos e aplicações das relações pedologiageomorfologia em regiões tropicais úmidas. Tópicos em Ciência do Solo, Viçosa, MG, v. 4, p. 145-192, 2005.

VIDAL-TORRADO, P.; LEPSCH, I. F.; CASTRO, S. S.; COOPER, M. Pedogênese em uma seqüência LatossoloPodzólico na borda de um platô na depressão periférica paulista. Revista Brasileira de Ciência do Solo, Viçosa, MG, v. 23, n. 4, p. 909-921, 1999. 
